\title{
Design and Construction of the Oil Palm Fruit Sorting Device Based on Color with PC Display
}

\author{
Takdir Tamba ${ }^{1 *}$ and Wahyuda Nababan ${ }^{2}$ \\ ${ }^{1,2}$ Department of Physics, Faculty of Mathematics and Natural Science, Universitas Sumatera Utara \\ 20155, Indonesia
}

\begin{abstract}
This research discusses the design and construction of an oil palm fruit sorting tool and a counter for the number of oil palm fruits that work automatically using the working principle of a color sensor. This tool can work automatically because it is controlled by an ATmega328 microcontroller. Overall this system consists of designing a color sensor, motor controller, conveyor, and power supply. Item detection consists of 328 microcontroller technology, color sensor, proximity sensor, LCD, IOT, and PC display. The testing stages of this tool include testing the sensor circuit, testing the servo motor circuit, and testing the automatic oil palm fruit sorting and counting tool. When the oil palm fruit is detected, the color sensor will take data. The captured data will be sent to the microcontroller and displayed to the LCD, IOT and PC. There are additional devices in the form of undercooked, ripe and past ripe separation bars by utilizing a DC servo motor.
\end{abstract}

Keyword: ATmega328, conveyor, IOT, LCD, DC motor, servo motor, color sensor.

Received 06 November 2019 | Revised [04 December 2019] | Accepted [14 February 2020]

\section{Introduction}

Companies always try to replace jobs that have been done by humans to be replaced with machine in the context of efficiency and increasing the quality of their production. In other words, many companies automate their production [1-3].

The loss of palm oil in the fresh fruit bunch (FFB) sterilization process is influenced by the content of crude palm fruit, the length of time for boiling and the steam pressure [4-5]. If the crude palm fruit content is high, then longer sterilization and higher steam pressure are required [6]. The loss of palm oil in the fresh fruit bunch (FFB) sterilization process is influenced by the content of crude palm fruit, the length of time for boiling and the steam pressure. If the crude palm fruit content is high, then longer sterilization and higher steam pressure are required. On the other hand, if the FFB is overripe, it will require a shorter sterilization time and lower steam pressure to reduce palm oil losses during the sterilization process. At this time the calculation of the content of crude palm fruit entering the factory is still carried out based on visual

\footnotetext{
*Corresponding author at: Jalan Biolteknologi no.1 Medan, 20155, Indonesia

E-mail address: takdir@usu.ac.id
} 
observations, so that the loss of palm oil in the sterilization process is still high, which is more than the standard of $0.3 \%$ [7].

\section{Methods}

The structural model of the device is given in Figure 1 while the flowchart is shown in Figure 2.

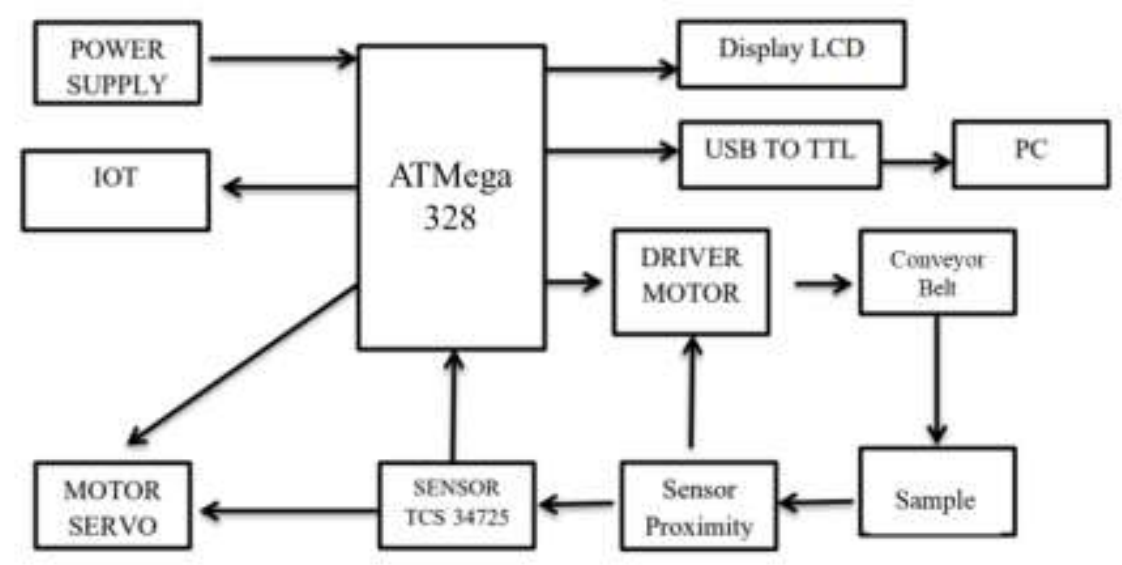

Figure 1. Block Diagram of the System

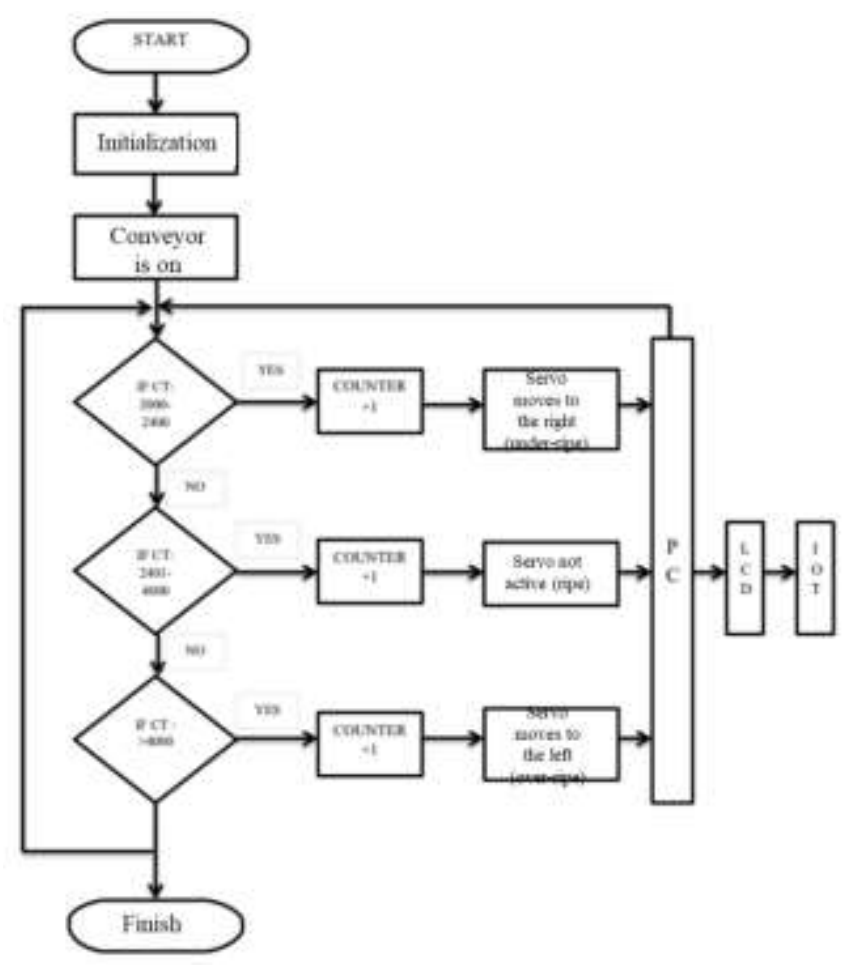

Figure 2. Flowchart of the System 


\section{Result and Discussion}

\subsection{TCS34725 Color Sensor Circuit Testing}

Detecting the color of the oil palm fruit was done by color sensor, while the fruit has been varied in the fraction of raw, ripe, and past ripe which then detects the level of maturity carried out by the color sensor. Table 1 shows the results.

Table 1. RGB Value on Oil palm Fruit

\begin{tabular}{cccccccccc}
\hline & \multicolumn{4}{c}{ Sensor 1 } & \multicolumn{4}{c}{ Sensor 2 } & $\begin{array}{c}\text { Color } \\
\text { No }\end{array}$ \\
\cline { 2 - 8 } & $\mathrm{R}$ & $\mathrm{G}$ & $\mathrm{B}$ & $\mathrm{CT}$ & $\mathrm{R}$ & $\mathrm{G}$ & $\mathrm{B}$ & $\mathrm{CT}$ & $\begin{array}{c}\text { Terature } \\
(\mathrm{K})\end{array}$ \\
\hline 1 & 173 & 293 & 273 & 3952 & 243 & 230 & 224 & 7597 & 5774 \\
2 & 726 & 618 & 382 & 4155 & 354 & 319 & 292 & 3113 & 3634 \\
3 & 799 & 410 & 311 & 2519 & 568 & 350 & 297 & 2211 & 2364 \\
\hline
\end{tabular}

\subsection{Proximity Sensor Testing}

The input and output functions of sensor 1 and sensor 2 testing to work properly shown in Table 2. Furthermore, the test carried out is by providing program instructions to read each input from the input component.

Table 2. Proximity Sensor Output Voltage Testing

\begin{tabular}{ccc}
\hline Proximity Sensor & On $(\mathrm{V})$ & Off $(\mathrm{V})$ \\
\hline Proximity 1 & 5 & 0 \\
Proximity 2 & 5 & 0 \\
\hline
\end{tabular}

\subsection{Power Supply Circuits Testing}

In the test, the input voltage from PLN is 220 Volt AC then it goes to the transformer to be changed to 12 Volt AC, then it is directed to the Diode of 12 Volt DC. After the measurement, the output voltage is 5 volts. It can be ascertained whether there is an error with the circuit or not. If measured, the result of an impure voltage output of 5 volts. This result is due to several factors, including the quality of each component used, the value is impure. In addition, the voltage on the grid is unstable. The following is the power supply output voltage data shown in Table 3.

Table 3. Power Supply Testing of ATMega 328

\begin{tabular}{cc}
\hline Input & Output \\
\hline 12 Volt & 5 Volt \\
\hline
\end{tabular}

\subsection{Whole Circuit Testing}

Testing the whole system is carried out to find out whether the entire circuit can run well; it is given in Table 4. Initially the proximity sensor will detect the object, then the color sensor will detect the RGB value that has varied its maturity. Furthermore, the results of the reading of this 
tool will be displayed on the LCD, PC and IOT. The RGB data on the TCS34725 sensor has a feature that provides a gain of 60 times to be able to distinguish colors specifically and in detail [8-10]. The following is the test data for the palm loose fruit count and separator based on the maturity fraction shown with the following conditions:

a. Sensor 1 is placed on the right side of the Conveyor Belt

b. Sensor 2 is placed on the left side of the Conveyor Belt

c. The Color Temperature value is obtained from the average value of CT sensor 1 and CT sensor 2

Table 4. The Data of The Whole Testing

\begin{tabular}{ccccccccccc}
\hline \multirow{4}{*}{ No } & \multicolumn{9}{c}{ Sensor 1 } & \multicolumn{6}{c}{ Sensor 2} \\
\cline { 2 - 7 } & $\mathrm{R}$ & $\mathrm{G}$ & $\mathrm{B}$ & $\mathrm{CT}$ & $\mathrm{R}$ & $\mathrm{G}$ & $\mathrm{B}$ & $\mathrm{CT}$ & $\begin{array}{c}\text { Colour } \\
\text { Temperature } \\
(\mathrm{K})\end{array}$ & $\begin{array}{c}\text { Maturity } \\
\text { level }\end{array}$ \\
\hline 1 & 173 & 293 & 273 & 3952 & 243 & 230 & 224 & 7597 & 5774 & under ripe \\
2 & 726 & 618 & 382 & 4155 & 354 & 319 & 292 & 3113 & 3634 & ripe \\
3 & 799 & 410 & 311 & 2519 & 568 & 350 & 297 & 2211 & 2364 & Over ripe \\
4 & 1691 & 898 & 567 & 2304 & 1655 & 728 & 508 & 2283 & 2298 & Over ripe \\
5 & 299 & 299 & 275 & 4054 & 264 & 239 & 230 & 4591 & 4322 & under ripe \\
6 & 1131 & 1148 & 1092 & 3767 & 395 & 371 & 357 & 5021 & 5021 & under ripe \\
7 & 396 & 252 & 209 & 3287 & 875 & 552 & 521 & 2808 & 3042 & ripe \\
8 & 868 & 433 & 301 & 2353 & 696 & 406 & 332 & 2188 & 2270 & Over ripe \\
9 & 745 & 403 & 665 & 3684 & 1038 & 767 & 665 & 2302 & 2993 & ripe \\
10 & 1057 & 1073 & 1013 & 4330 & 260 & 251 & 236 & 4552 & 4580 & under ripe \\
11 & 2597 & 2767 & 1661 & 3153 & 269 & 210 & 197 & 3808 & 3480 & ripe \\
12 & 779 & 749 & 762 & 3931 & 268 & 246 & 226 & 5102 & 4516 & under ripe \\
13 & 2428 & 1020 & 688 & 2395 & 957 & 434 & 382 & 2168 & 2281 & Over ripe \\
14 & 460 & 308 & 286 & 2983 & 3446 & 1669 & 1483 & 2790 & 2967 & ripe \\
15 & 1671 & 1562 & 1201 & 3937 & 321 & 283 & 255 & 3966 & 3951 & ripe \\
16 & 1054 & 1067 & 1006 & 3073 & 373 & 331 & 288 & 4980 & 4426 & under ripe \\
17 & 2428 & 1020 & 688 & 2395 & 957 & 434 & 382 & 2168 & 2281 & Over ripe \\
18 & 942 & 432 & 312 & 2257 & 1669 & 708 & 542 & 2190 & 2223 & Over ripe \\
19 & 1523 & 876 & 535 & 2548 & 1121 & 544 & 449 & 2381 & 2464 & ripe \\
20 & 1327 & 631 & 463 & 2389 & 560 & 463 & 292 & 2318 & 2353 & Over ripe \\
\hline
\end{tabular}

In this test, twenty experiments were carried out to determine the accuracy of the calculations. To determine the accuracy of the sensor in detection, testing was carried out by providing different samples. Twenty tests were carried out for fruit with different colors.

\section{Conclusion}

From the results of designing tools to testing and discussion of the system, the authors can draw conclusions that designed a tool that can count and sort oil palm fruit based on the level of fruit color maturity has been successfully designed using ATMega328 microcontroller. This tool works to detect the color of the oil palm fruit and count the number of fruit samples by utilizing a color sensor and a servo motor that will sort the fruit by size. The working principle of the oil 
palm fruit sorting tool uses a microcontroller-based color, namely when the fruit runs on the conveyor belt and passes the proximity sensor beam, the conveyor stops then sensor 1 and sensor 2 identify it, if the fruit is categorized as under ripe by the color sensor, the microcontroller gives instructions for moving servo signposts. to the right, if the fruit is categorized as ripe by the color sensor, the microcontroller gives instructions to the servo signpost off and if the fruit is categorized as ripe by the color sensor, the microcontroller gives instructions for the servo signpost to move to the left.

\section{REFERENCES}

[1] V. S. Morozov, "On the Degree of Automatization of Machine-Tools," Avtomat. $i$ Telemekh., no. 5, pp. 41-50, 1936.

[2] E. Gatbonton and N. Segalowitz, "Creative Automatization: Principles for Promoting Fluency within a Communicative Framework," TESOL Quarterly, vol. 22, no. 3, pp. 473492, 1988.

[3] M-Y. Li and X-R. Zhang, "Theoretical Analysis on Automatization and Human-Machine Combination," in 2009 International Conference on Intelligent Human-Machine Systems and Cybernetics, vol. 1, IEEE, 2009.

[4] A. K. M. Omar, T. L T. Norsalwani, M. S. Asmah, Z. Y. Badrulhisham, A. M. Easa, F. M. Omar, M. S. Hossain, M. H. Zuknik and N. A. N. Norulaini, "Implementation of the Supercritical Carbon Dioxide Technology in oil Palm Fresh Fruits Bunch Sterilization: A review," Journal of CO2 Utilization, vol. 25, pp. 205-215, 2018.

[5] C. J. Vincent, R. Shamsudin and A. S. Baharuddin, "Pre-Treatment of Oil Palm Fruits: A Review," Journal of Food Engineering, vol. 143, pp. 123-131, 2014.

[6] N. A. Hadi, N. M. Han, C. Y. May and M. A. Ngan, "Dry Heating of Palm Fruits: Effect on Selected Parameters," American Journal of Engineering and Applied Sciences, vol. 5, no. 2, pp. 128-131, 2012.

[7] A. Thoriq, "Pengembangan Sistem Deteksi Kematangan Tandan Buah Segar (TBS) Kelapa Sawit Berbasis Spektrum Cahaya Tampak," M.S. thesis, Program Program Pasca Sarjana Teknik Mesin Pertanian dan Pangan, Institut Pertanian Bogor, Bogor, 2013.

[8] R. B. N. Scharff, R. M. Doornbusch, X. L. Klootwijk, A. A. Doshi, E. L. Doubrovski, J. Wu, J. M. P. Geraedts and C. C. L. Wang, "Color-Based Sensing of Bending Deformation on Soft Robots," In 2018 IEEE International Conference on Robotics and Automation (ICRA), pp. 4181-4187, IEEE, 2018.

[9] L. A. Greenawald, G. R. Boss, J. L. Snyder, A. Reeder and S. Bell, "Development of an Inexpensive RGB Color Sensor for the Detection of Hydrogen Cyanide Gas," ACS sensors, vol. 2, no. 10, pp. 1458-1466, 2017.

[10] J. C. Shovic, "Sensing your IOT Environment," in Raspberry Pi IoT Projects: Prototyping Experiments for Makers, Switzerland AG: Apress Springer Nature, 2016, 9-61. 